\title{
Research on Chinese Listening Teaching as a Foreign Language Based on Schema Theory
}

\author{
Shengguang $\mathrm{Yan}^{1}$, Hefei $\mathrm{Li}^{2}$ \\ ${ }^{1}$ International Education Center, North China University of Science and Technology, \\ Tangshan, Hebei, China, 063000 \\ ${ }^{2}$ President's Office, North China University of Science and Technology, Tangshan, Hebei, \\ China, 063000
}

Keywords: Chinese Listening Teaching, Schema Theory, Teaching Chinese as a Foreign Language

\begin{abstract}
Listening teaching is an important and difficult part of teaching Chinese as a foreign language. Aiming at the problems existing in listening teaching, teachers should strengthen the guiding role of teachers in listening teaching. This paper gives a brief introduction to schema theory and illustrates the important role of schema theory in listening comprehension. According to the characteristics of schema theory and the characteristics of listening teaching, teachers can try to establish the schemas of the three stages of listening, which are the pre-listening stage, while-listening stage and post-listening stage, to improve the students' abilities to understand the listening text.
\end{abstract}

\section{Concept of Schema Theory}

Schema theory is a theory based on the representation and storage of knowledge organized around a subject. The concept of schema first came from the German philosopher Kant in nineteenth Century. The test shows that people have no meaning to remember the story according to the facts, but the fact that they have to assimilate with the cultural characteristics of the process. People change the memory of stories to keep them in line with their cultural concepts. The "adaptation" of the story reflects people's cultural schema. Schema is a way that people understand the world, in the memory, the schema helps memory retrieval, and there are many forms of schema. He thinks that the existence of schemata can explain why people change some of the details when they recall stories. A schema is a representation of new knowledge and brain have some knowledge and information organic connected, is a kind of semantic memory structure and storage form, is a memory arrangement and a semantic generalization of the understanding of the information. Schema is the knowledge that has been stored in the minds of people and has been established by the information network, refers to each person in the past has been the knowledge of the letter. The establishment of the pattern of human brain tissue and actively reflect on the past experience and knowledge, learning is stored in the long-term memory of the information has been the process of new knowledge and learning how these new knowledge enrich and expand to their original information system the process of Schema in the network. Carroll divides the schema into the content schema and the formal schema. James there is another kind of method, which is divided into three types: language schema, content schema and formal schema.

\section{Functions of Schema Theory in Listening Comprehension}

Function of Forecast. Prior to reading, schema plays a role in expectation. It can organize the information storage and extract them. This sentence also applies to listening comprehension. The schema can play a predictive role before listening. The schema in memory is to be arranged in 
different Lenovo, connected to each other interaction, when a schema is activated when extracting, all associated with it a series of schemata are likely to be activated in a selected state, thereby providing a positive preparation for the listener to understand the state of material, so a listener expected to hear about it, the listener to guess the unknown information behind according to the existing schema, and constantly confirm or understand material information correction is expected to psychological activities. Many scholars believe that the schema is composed of empty slots and default values. By filling some bits and pieces of information that can be used to activate a schema in a network of information, the schema will enable the other schemas to be connected to it. So the listener can obtain the corresponding information from the activated schema to predict and associate the content to be heard.

Function of Supplement. In the process of listening comprehension, sometimes even a sentence in the lack of a few words, we also can roughly guess the default meaning, sometimes the whole can accurately fill out the missing words, will not affect our understanding of the meaning of the theme. The ability of the listener is based on the listener's language knowledge, store it is self-evident omit some details of the content in the listener's mind is often in the long-term memory of the old knowledge and information, past situations and on the basis of the experience of listening materials, the difference of information requires the listener according to the corresponding schema knowledge in his mind to supplement, when the listener has a material schema is activated, it will produce a series of psychological activities, which part of the default materials are added, and this supplement and materials to express the meaning is often caused by. As the schema is an abstract knowledge structure, it summarizes the different types of specific information and examples. As long as the activation of the corresponding schema, the listener can omit the information to be filled at the same time, also has the integration of schema information. The function of the integration process in new information and storage is the human brain will get their schemata in the coordination process schema.

Function of Filtering. Schema is selective in processing the input information. After listening to the relevant clues, processed activated schemata for information storage provides a framework that can be organized in the schema will be long term memory, and schema irrelevant information is difficult to be in the organization, so it is easy to forget. It can be seen that the schema is helpful to the distribution of attention. This is also very important for listening comprehension, as it is well known that listening comprehension is not as important as reading comprehension. If - man heard a bunch of information, but cannot distinguish between primary and secondary, will undoubtedly increase the difficulty of hearing, because he was listening to the time do not know what information would be useful, unable to properly allocate the limited attention and memory. As a kind of knowledge frame structure, the schema has a strong ability to identify and select the two schemata. This knowledge selectively determines the experience to pay attention to what, and what to ignore. The schema can be viewed as a filter when the listener intake of information, the information will be consistent with some schema assimilation in, and inconsistent with the information will be limited to filter out when learners will apply it to the study of relevant schema is activated after..

\section{Applications of Schema Theory in Chinese Listening Teaching as a Foreign Language}

Warm-up of Pre-listening Stage. In listening teaching, the language schema refers to the basic knowledge of the listener in the aspects of pronunciation, vocabulary, sentence pattern and grammar. Language schema is the basis of listening comprehension, and it is not essential to identify the words, phrases and sentences in the listening materials. Teachers should first design some teaching 
activities, to eliminate the obstacles in the language level of the students. Teachers can give students homework assignments to the next class listening to the words, sentences, expressions and grammar knowledge for students to preview. You can also organize some activities in the classroom to enhance the students' impression of the language knowledge, such as using the language knowledge to explain the new words. Show the new words with some kind and picture. Differentiate and understand the meaning of words in phrases and sentences. Let the students make sentences with the new words and sentences. Set the scene for students may be used in the listening material words, sentence let the students act the dialogue will appear in the guess listening vocabulary, writing on the blackboard the student presented words, let us discuss. Teachers can put new words according to appear in the listening materials in order, and form a network structure and Related words, deepen the impression of the students, effectively activate their language schema, which is conducive to the understanding of the content of the hearing. This is the process of the transfer of schemata in the students' mind. Teachers should fully activate the students' original schema at this stage, and help students to establish a good relationship with the original schema. Teachers should know the listening materials in the language knowledge to explain, to introduce background knowledge to guide the students to actively search for the original schema in the brain. This is a classification process of the schema. We classify the text which we want to hear to which schema. Teachers should try to establish a new schema for the students to eliminate the obstacles. So that students will not listen to the process because of the individual words do not understand the impact of its organizational structure to assimilate new information. Students will not lose their interest in listening comprehension because of the background of language materials. Teachers should actively guide students through the differences between the old and the new schema to enrich their own schema structure.

Comprehension of While-listening Stage. Teachers should guide students to take the issue to listen to, listen to the time, with a clear purpose. In the listening materials, the main information and secondary information and redundant information are often included. It is able to meet the main information required to answer the questions. Secondary information is that although there is no direct relationship with the answer, but it helps to understand the content of the relevant information. Redundant information is information that has nothing to do with the answer. Therefore, in the process of listening comprehension, it is not possible to make students understand each sentence. Teachers should train the students to catch the key words, grasp the main information in the text, the reasonable use of secondary information, but also the ability to eliminate redundant information interference. Teachers should ask students to listen to the process, the language information to hear the notes down, the sound signal into a text signal, in order to review and access. At the beginning of the notes, the teacher should be a demonstration of what students should remember, how to remember, and to check the student's record, wait until the students basically have this ability, and then let the students to record their own. Teachers can make students use their own mother tongue and symbol record. When you hear the numbers, write it down at once, or you will soon forget. For multiple-choice questions, before listening to let the students look at the options, understand the possible at the sound of the content, then let the students when listening to, watching the recording options, which option mentioned, do a mark next to it, in order to help memory, as the basis to choose the correct answer. If the assimilation process is carried out smoothly, the students' schema is enriched, which is the most important link in the teaching of listening.

Consolidation of Post-listening Stage. Each student's learning background, the background of life is not the same, so the schema, schema network in mind is different, each person capture and understand information is also very different, in order to avoid the wrong understanding, after 
listening to the establishment of the pattern is very necessary, this is a new type of arrangement and adjustment the. At this stage, teachers should review the listening materials again, and make the necessary classification and summary of the listening materials, and make the necessary complement and carding to the relevant issues. It can be transferred to long-term memory storage, become a part of the listener knowledge system. Deepen teachers just explain, students doing wrong or re play did not understand the place. This kind of listening teaching mode misses the opportunity to deepen the understanding and consolidate what they have learned. In the listening phase, the schema is activated to the short-term memory, and the new information is processed. At the stage of listening, teachers should guide students to process the information in a timely manner, and transfer the schema stored in short-term memory into long-term memory. Teachers can take some measures to help students to consolidate schema questions or to repeat. Teachers ask questions about the content that has just been heard. This can promote students to understand the content of listening, deepen the impression, while teachers can also detect the degree of listening comprehension of students. Teachers let students listen to the content of the repeat, which can not only help students to recall the information, to consolidate the schema, but also the ability to exercise their oral expression and the general effect of the ability. After listening to consolidate the students can deepen the understanding of the information, the knowledge stored in long-term memory, to prepare for the future of listening comprehension. It should be noted that the above teaching activities can be selectively done. The post-listening activities in the whole listening teaching activities account for the smallest proportion.

\section{Conclusion}

Listening comprehension is a complex mental process. Listening teaching is an important part of teaching Chinese as a foreign language. The introduction of schema theory in the listening teaching can give full play to the students' cognitive abilities and improve their abilities of remembering and understanding the listening materials. In the teaching of listening, teachers should continue to use and improve the applications of schema theory to make the schema theory and listening teaching integrate better.

\section{References}

[1] Zhao Xin, Journal of Liaoning Administration College, Vol. 14 (2012) No 12, p.109-114

[2] Wu Jian, Wan Duo, Journal of Jixi University, Vol. 11 (2011) No 1, p.53-55

[3] You Yuling, Journal of Language and Literature Studies, Vol. 30 (2010) No 15, p.73-74

[4] Chen Xiaozi, Journal of Beijing Institute of Education, Vol. 28 (2014) No 2, p.53-56 